\title{
Postoperative findings in endoscopic endonasal surgery of the skull base
}

\begin{abstract}
Since the introduction of endonasal endoscopic skull base surgery the exclusive purpose in the management of skull base neoplasms has been to increase survival rates. Recently, given the improved prognosis achieved, more attention has been focused on the functional outcomes such as nasal symptoms and quality of life (QOL). The purpose of this review is to assess the functional outcomes after endonasal endoscopic skull base surgery.
\end{abstract}

Keywords: endoscopic surgery, skull nase, quality of life, nasal symptoms
Volume 6 Issue 2 - 2017

\author{
Cristobal Langdon, 1,3 Alfonso Santamaria, ${ }^{\prime}$ \\ Arturo Cordero, ,,3 Mauricio Lopez, ${ }^{1,3}$ \\ Joaquim Ensenat, ${ }^{2}$ Isam Alobid 1,3 \\ 'Otorhinolaryngology Department Rhinology Unit and Smell \\ Clinic Universitat de Barcelona, Spain \\ ${ }^{2}$ Neurosurgery Department Hospital Clinic Universitat de \\ Barcelona, Spain \\ ${ }^{3}$ Clinical and Experimental Respiratory Immunology IDIBAPS \\ Barcelona, Spain
}

\author{
Correspondence: Cristobal Langdon Rhinology Unit and \\ Smell Clinic Dept of Otorhinolaryngology Hospital Clinic \\ Universitat de Barcelona c Villarroel 170 Barcelona 08036, Spain, \\ Tel 34- 932279 872, Email clangdon@clinic.ub.es
}

Received: October 28, 2016 | Published: February 23, 2017
Abbreviations: QOL-AGHDA, quality of life-assessment of growth hormone deficiency in adults; QLS-H, hypopituitarism quality of life satisfaction; ASB-QOL, previous skull base quality of life; HDQOL, hormone deficiency-dependent quality of life; ACROQOL, acromegaly quality of life; PA-QOL, pituitary adenoma quality of life; ADDIQOL, addison quality of life; SNOT, sinonasal outcome test; RSOM, rhinosinusitis outcome measure; ISDN, rhinosinusitis disability index

\section{Introduction}

There has been a considerable increase in the use of extended nasal endoscopic approaches for skull base lesions over the last two decades. The progress and development of these endoscopic techniques are mainly due to the ever increasing knowledge of endoscopic anatomy, technological advances and the use of vascularized flaps for reconstruction of the skull base. ${ }^{1}$ As in endoscopic sinus surgery the extended approaches can cause a series of postoperative morbidities, like crusting and posterior rhinorrhea, especially in those cases requiring a nasoseptal flap reconstruction..$^{2,3}$ All sinus surgery could cause a mechanical damage of the sinus mucosa, which would require a subsequent healing process. The reepithelization by stratified epithelium occurs in a week, hair cells appear in 3weeks and complete recovery of the sinus epithelium occurs within $6-8$ weeks. ${ }^{4}$ Given this, Ginzel \& Illum ${ }^{5}$ conclude that one must wait until at least three months to assess the clinical and postoperative symptoms. Regarding to post-surgical quality of life Georgalas et al., ${ }^{6}$ have observed that the negative impact of the nasoseptal flap in the quality of life, is mainly due to an increased tendency to headaches and reduced smell, but improves over time especially in thosepatients with secreting pituitary tumors. Conversely, Alobid et al., ${ }^{2}$ found no differences between the groups of non functioning tumors and functioning pituitary tumors.

Since the use of endoscopic skull base surgery has expanded, there have been great efforts to develop specific questionnaires of quality of life for skull base and pituitary surgery (Table 1). Until now, the following tests have been applied in English literature; Quality of Life-Assessment of Growth Hormone Deficiency in Adults (QOLAGHDA) ${ }^{7}$ Hypopituitarism Quality of Life Satisfaction (QLS-H) ${ }^{8}$ Previous Skull Base Quality of Life (ASB-QOL), ${ }^{9}$ Hormone Deficiency-Dependent Quality of Life ( HDQOL) ${ }^{10}$ Acromegaly Quality of Life (ACROQOL), ${ }^{11}$ Pituitary Adenoma Quality of Life (PA-QOL), ${ }^{12}$ Cushing Quality of Life, ${ }^{13}$ Addison Quality of Life (AddiQOL), ${ }^{14}$ or ASK nasal inventory. ${ }^{15}$ The handicaps of these tests are that they do not include specific areas about quality of life and cancer, visual defects, hormonal deficiency and sinonasal symptoms. In the next article we will discuss the impact of endoscopic skull base surgery according to the following topics:
a. Sinus symptoms
b. Mucociliary clearance
c. Quality of life
d. Imaging findings

\section{Sinonasal symptoms}

In the last decade, endoscopic skull base surgery (ESBS) has had a massive development in terms of experience of the surgeon and technological advancement of the instruments, all of which has made possible to address larger and more complex tumors. As a result of the latter, patients suffer large anatomical and functional changes of the sinonasal cavity, therefore, it is expected postoperatively patients presents functional sinus pathology. It is in the immediate postoperative period (2-4weeks) when nasal symptoms are more evident, usually patients refers dense anterior and posterior rhinorrhea, nasal congestion, facial pain and headaches. ${ }^{16}$ Currently nasal symptoms are measured according to the visual analogue scale and/or by different questionnaires that measure their impact on quality of life. The most used are the Sinonasal Outcome Test 20 (SNOT-22), Rhinosinusitis outcome measure (RSOM-31) and the Rhinosinusitis Disability Index (ISDN). In one of the first studies about posterior 
nasal symptoms in skull base surgery, de Almenida et al. ${ }^{3}$ observed that the most frequent finding one month postoperative were nasal crusts (98\%), and at least half of the patients continue with nasal crusts for 3 months post-surgery; the time of disappearance of the crusts was related to the complexity of the surgery but not to the use of fat or flaps to close the defect of the skull base. Recently, Alobid et al., ${ }^{2}$ studied a series of patients undergoing transsphenoidal ESBS (38 patients) or extended surgery with nasoseptal flap reconstruction (17 patients), they observed that in the postoperative period $28 \%$ of the patients who undergone transsphenoidal approaches and $64 \%$ who undergone extended surgery had posterior rhinorrhea. Graham et al., ${ }^{17}$ compared the nasal symptoms in patients undergoing endoscopic or open surgery, noting that patients in the endoscopic surgery group had a lower score of nasal symptoms. Pant \& McCoul et al. ${ }^{18,19}$ showed that the SNOT-22 scores and nasal symptoms increased moderately in the immediate postoperative period but subsequently returned to their preoperative values. Following the same line of study, Balaker et al. ${ }^{16}$ found that nasal symptoms were significantly improved over time but posterior rhinorrhea persisted in time until at least one year after surgery.

Table I Articles about quality of life and nasal symptoms in surgery ESBCAcro-QOL:Acromegaly Quality of Life;Addi-QOL:Addison's Quality of Life;ASB-QOL: Anterior Skull Base Quality of Life; ALHR: Atkinson Life Happiness Rating; CES-D: Centre for Epidemiologic Studies Depression Scale; Cushing QOL: Cushing Quality of Life; HDQOL: Hormone Deficiency Quality of Life; SF-36: 36-Item Short Form Health Survey; QLS-H: Quality of Life Satisfaction Hypopituitarism; QOL-AGHDA: Quality of Life Assessment for Growth Hormone Deficiency in Adults; MDS: Midface Dysfunction Scale; PHQ: Patient Health Questions; RSOM31: Rhinosinusitis Outcome Measure; UOW-QOL: University of Washington quality of life questionnaire

\begin{tabular}{lllllll}
\hline Reference & Method & Type of Pathology & Items & $\begin{array}{l}\text { N. of } \\
\text { Items }\end{array}$ & $\begin{array}{l}\text { N. of } \\
\text { Answers }\end{array}$ & \multicolumn{1}{c}{ Results } \\
Diaz et al. [50] & & Skull Base Chordomas & $\begin{array}{l}\text { Health, pain, social, } \\
\text { mental }\end{array}$ & 36 & 6-Feb & Worse quality of life \\
\hline & & $\begin{array}{l}\text { health, limitations, } \\
\text { relationships, vitality, } \\
\text { SF-36 }\end{array}$ & $\begin{array}{l}\text { personal perception. } \\
\text { Depression. }\end{array}$ & \\
& & &
\end{tabular}

Major depression

9

PHQ-9

Castelnuovo et Malignant tumors of the function,

al. [45] ASB-QOL skull base.

vitality, specific

symptoms,

performance.
The radical

endoscopic resection

needs at least a year I-12 Month

to recover II or part

of QoL

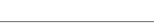

\begin{tabular}{|c|c|c|c|c|c|c|c|}
\hline $\begin{array}{l}\text { Abergel et al. } \\
{[5 \mathrm{I}]}\end{array}$ & ASB-QOL & Tumors of the skull base. & $\begin{array}{l}\text { Pain, physical } \\
\text { function, } \\
\text { vitality, specific } \\
\text { symptoms, } \\
\text { performance. }\end{array}$ & 32 & 5 & $\begin{array}{l}\text { Some domains of } \\
\text { QoL are better with } \\
\text { endoscopic than } \\
\text { open approach. }\end{array}$ & 12 Month \\
\hline
\end{tabular}

\begin{tabular}{|c|c|c|c|c|c|c|}
\hline $\begin{array}{l}\text { Georgalas et } \\
\text { al. [6] }\end{array}$ & RSOM-3I & $\begin{array}{l}\text { Benign tumors of the } \\
\text { skull base. }\end{array}$ & $\begin{array}{l}\text { General, Nose, } \\
\text { Ocular, } \\
\text { Hearing, Sleep. }\end{array}$ & 31 & 5 & $\begin{array}{l}\text { Secreting tumors are } \\
\text { a negative factor in } \\
\text { the quality of life. }\end{array}$ \\
\hline $\begin{array}{l}\text { Lovas et al. } \\
{[14]}\end{array}$ & Addi-QoL & $\begin{array}{l}\text { Patients with Addison's } \\
\text { Disease }\end{array}$ & Physical, emotional & 36 & 5 & \\
\hline \multirow[t]{3}{*}{$\begin{array}{l}\text { Palme et al. } \\
\text { [52] }\end{array}$} & FACT & $\begin{array}{l}\text { Patients with anterior } \\
\text { skull base cancer }\end{array}$ & $\begin{array}{l}\text { Physical, social, } \\
\text { physical } \\
\text { function, } \\
\text { emotional, social, } \\
\text { family. }\end{array}$ & 38 & 5 & $\begin{array}{l}\text { RecurrenceRTandMDSpresented lower } \\
\text { QOL scores }\end{array}$ \\
\hline & & & Depression & & & \\
\hline & & & $\begin{array}{l}\text { and happiness sight, } \\
\text { hearing, taste, touch }\end{array}$ & & & \\
\hline
\end{tabular}


Table Continued...

\begin{tabular}{|c|c|c|c|c|c|c|c|}
\hline Reference & Method & Type of Pathology & Items & $\begin{array}{l}\text { N. of } \\
\text { Items }\end{array}$ & $\begin{array}{l}\text { N. of } \\
\text { Answers }\end{array}$ & Results & $\begin{array}{l}\text { Valoration } \\
\text { Time }\end{array}$ \\
\hline & & & & 20 & 4 & & \\
\hline & CES-D & & & I & 11 & & \\
\hline & ALHR & & & 4 & 5 & & \\
\hline & MDS & & & & & & \\
\hline
\end{tabular}

\begin{tabular}{|c|c|c|c|c|c|}
\hline \multirow[t]{2}{*}{ [13] } & & \multicolumn{2}{|c|}{ Patients with Cushing's Disease } & \multirow[t]{2}{*}{12} & \multirow[t]{2}{*}{5} \\
\hline & \multicolumn{3}{|c|}{ Cushing QoL } & & \\
\hline $\begin{array}{l}\text { McMillan et al. } \\
{[10]}\end{array}$ & HDQOL & $\begin{array}{l}\text { Patients with } \\
\text { hypopituitarism }\end{array}$ & $\begin{array}{l}\text { Work, family, social, } \\
\text { sex, } \\
\text { appearance, self- } \\
\text { confidence, } \\
\text { physical capabilities, } \\
\text { leisure, } \\
\text { travel, motivation, } \\
\text { spiritual, } \\
\text { society's reaction, } \\
\text { future } \\
\text { worries, }\end{array}$ & 20 & 7 \\
\hline
\end{tabular}



\begin{tabular}{|c|c|c|c|c|c|c|}
\hline Badia et al. [53] & Patients with acromegaly & $\begin{array}{l}\text { Physical, } \\
\text { psychological } \\
\text { apperance, } \\
\text { physiological } \\
\text { relations }\end{array}$ & 22 & 5 & & \\
\hline \multicolumn{7}{|c|}{ Acro-QOL } \\
\hline Gil et al. [9] & $\begin{array}{l}\text { Patients with anterior } \\
\text { skull base cancer }\end{array}$ & $\begin{array}{l}\text { Performance } \\
\text { physical } \\
\text { function, vitality, }\end{array}$ & 35 & 5 & $\begin{array}{l}\text { Malignancy, RT } \\
\text { and comorbidityis } \\
\text { associated with a } \\
\text { lower score. }\end{array}$ & $\begin{array}{l}\text { More than } 3 \\
\text { months }\end{array}$ \\
\hline
\end{tabular}


Table Continued.

\begin{tabular}{|c|c|c|c|c|c|c|c|}
\hline Reference & Method & Type of Pathology & Items & $\begin{array}{l}\text { N. of } \\
\text { Items }\end{array}$ & $\begin{array}{l}\text { N. of } \\
\text { Answers }\end{array}$ & Results & $\begin{array}{l}\text { Valoration } \\
\text { Time }\end{array}$ \\
\hline & & & \multicolumn{5}{|l|}{ pain, specific } \\
\hline & ASB-QOL & & \multicolumn{5}{|l|}{ symptoms, influence } \\
\hline & & & on & & & & \\
\hline
\end{tabular}

\begin{tabular}{lllll}
\hline Herschbach et al. [8] & $\begin{array}{l}\text { Patients with growth } \\
\text { hormone deficiency/ } \\
\text { hypopituitarism }\end{array}$ & Physical, emotional 9 & 5 & 9 \\
\hline
\end{tabular}

QLS-H

\begin{tabular}{|c|c|c|c|}
\hline McKenna et & $\begin{array}{l}\text { QOL- } \\
\text { AGHDA }\end{array}$ & Patients with growth hormone deficiency & 25 \\
\hline
\end{tabular}

Normal sense of smell, requires the integrity of the olfactory epithelium for proper functioning, in cases of lateral or anterior skull base surgery (without affecting cribriform plate) is possible to conserve the olfactory mucosa in a large percentage of patients. Despite the above, in cases where there is involvement of the cribriform plate and / or olfactory bulb or must perform an extended approach; the integrity of the olfactory mucosa is affected almost entirely with subsequent olfactory dysfunction for the patient. To date, there are few studies that examine olfactory dysfunction through olfactometry in patients operated by ESBS. Hart et al., ${ }^{20}$ studied 45 patients who underwent endoscopic endonasal hypophysectomy by olfactometry test of the University of Pennsylvania (UPSIT), they observed that patients had a lower ability to smell a month after surgery but after three months there were no significant differences in compare to preoperative scores. Rotenberg et al., ${ }^{21}$ observed that at 6 months postsurgery patients undergoing endoscopic endonasal hypophysectomy and nasoseptal flap reconstruction presented hyposmia according to the score obtained in the UPSIT. In our series of 50 patients undergoing ESBS, 36 with transsphenoidal surgery and 14 with extended surgery, we observed that patients undergoing extended approach and nasoseptal flap reconstruction had higher olfactory dysfunction at 3 months post-surgery compared to patients undergoing transsphenoidal surgery. ${ }^{2}$

\section{Mucociliary clearance (MCC)}

Mucociliary clearance (MCC) is a primary defence mechanism of the upper and lower airways and disruption of this process, whether acquired or inherited, predisposes an individual to chronic upper and lower airway infections. ${ }^{22}$ The MCC could be hampered for two main reasons:

a. Defaults in the movements of the cilia (genetic defects or temporary dysfunction)

b. Dehydration of the mucus leads to increased viscosity and the ciliary clearance becomes thereby ineffective. In the first group we have primary (genetic) and secondary (infection or inflammation) ciliary diskinesia while in the second group we found cystic fibrosis, COPD, or asthma patients. Many factors influence the $\mathrm{MCC}$, among them are: temperature, humidity, trauma, smoking, viral infections, chronic sinusitis, allergic rhinitis, adenoid hypertrophy, deviated septum, sinus surgery, fibrosis cystic, chronic bronchitis and asthma ${ }^{23}$. At present, none of the methods studying MCC is the ideal, and there is a variety of investigational methods and techniques for its study. There have been very different results for the MCC, with transport time measurements of various substances, transport rate and ciliary beat frequency. The most commonly used method is the saccharine test, introduced by Andersen et al. ${ }^{24}$ and since then it has been used in multiple studies for evaluating the MCC. Although it depends on a subjective factor, it gives a well-defined time of MCC, since subjects clearly described the perception of sweet taste. There are some who criticize the use of saccharin particles as a measure of mucosal transport, ${ }^{25,26}$ but there are studies that show a good correlation between the time of MCC measured by saccharine test and ciliary beat frequency determined by photometry ${ }^{27,28}$ as well as a significant negative correlation with the transport speed measured by resin particles labelled with 99Tc. ${ }^{29}$ The test is performed in a room at ambient temperature, where the patient is requested not to perform forced breaths or sudden movements during the test. A $1 \mathrm{~mm}$ saccharin particle is applied at $1 \mathrm{~cm}$ from anterior end of the inferior turbinate. It is determined the time required by the patient to perceive sweetness. Patients are asked to report any change in taste without warning them that they will receive a sweet flavour.

Few studies have assessed the impact of sinus surgery in the MCC. Alobid et al., ${ }^{2}$ studied the MCC in patients undergoing endoscopic transnasal-transsphenoidal approaches (TTEA) or extensive endonasal approach (EEA) for resection of skull base tumors. They found that patients had a prolonged MCC time for three months after surgery. They also showed that patients with EEA had a longer MCC than those operated by TTEA. Moreover, several studies have concluded that septoplasty improve the MCC. David et al., ${ }^{30}$ showed that the MCC improved in patients who were undergoing septoplasty, they also found no significant difference in the MCC between the blocked nasal cavity and the opposite side. Moreover, Shone et al., ${ }^{31}$ studied mucociliary function by saccharin test in three groups of patients (septoplasty, endoscopic polypectomy and turbinectomy) and observed that patients with preoperative mucociliary dysfunction did 
not improve its function after surgery. Singh et al., ${ }^{32}$ recently studied the improvement of MCC in 43 patients undergoing endonasal endoscopic surgery for chronic rhinosinusitis with or without polyposis. They noted that the MCC measured by the saccharin test improved significantly following endoscopic sinus surgery.

\section{Quality of life}

Quality of life is a multidimensional concept that measures the relationship of a series of physical and psychosocial factors that describe the ability of an individual to make his life and get satisfaction from it, thus showing the degree of comfort and satisfaction. ${ }^{33}$ Quality of life after treatment is a fundamental value for the patient; it probably is the most important parameter after survival. The analysis of quality of life is based on measuring the patient's opinion about different aspects of life that may have been modified after the treatment. These dimensions or domains include: physical activity, psychological state, social interaction and somatic perception. ${ }^{34,35}$

The surgical success should be defined as the equilibrium between the tumour surgical resection (disease-free margins) with a minimal functional impact. The advantages and limitations of endoscopic skull base surgery have been extensively studied. ${ }^{36,37}$ However, fewer studies have been done on the functional impairment and quality of life. It is very difficult to conduct well-structured studies with high level of evidence for quality of life due to the low prevalence of surgical pathology of the skull base, the variation of the localization, different surgical approaches and reconstruction methods. Page et al., ${ }^{38}$ were the first researchers that used a generic questionnaire of quality of life to study patients undergoing endoscopic pituitary surgery and showed no difference in quality of life when compared with patients who underwent mastoidectomy. Johnson et al., ${ }^{39}$ compared patients according to the pituitary pathology with the normal population. They found that patients with acromegaly had impaired physical function while patients with Cushing syndrome showed deterioration in all the evaluated parameters except for one domain. Patients with prolactinoma had mental deterioration, but patients with a non-functioning adenoma presented impairments in the physical and mental spheres. ${ }^{39}$ Karabatsou et al. ${ }^{40}$ conducted the first study on quality of life in patients undergoing pituitary adenoma by endonasal endoscopic surgery; they showed that these patients had mild postoperative deterioration on the SF-36. Georgalas et al., ${ }^{6}$ recently observed that patients with hormone-secreting tumors had greater postsurgical impairment of quality of life. Alobid et al., ${ }^{2}$ observed similar results to those previously mentioned; however, they did not find differences between functioning and non-functioning adenomas. Consistent with the latter study, Suberman et al., ${ }^{41}$ used the ISDN and observed no differences between preoperative and postoperative scores in patients with or without functioning pituitary pathology. Patients with extended endonasal approaches are a challenge, since they are usually cancer patients with a significant physical, cognitive, emotional or social deterioration. ${ }^{42}$ Martinez et al., ${ }^{43}$ assessed the quality of life in patients with sinonasal carcinomas after surgery and observed that they had a significant deterioration in the items of anxiety, physical activity and emotional state. It is possible that these findings correlate more closely with adjuvant treatments and oncological disease than the surgery itself. A recent meta-analysis confirmed that patients undergoing oncologic pathology have a lower quality of life compared to patients with benign tumors independent of the type of surgical technique. ${ }^{44}$ Castelnuovo et al., ${ }^{45}$ studied a cohort of 153 patients who received adjunctive therapy and found that they had higher scores using the questionnaire for surgery anterior skull base (ASBS-Q). It seems that their reduction in quality of life was secondary to the adjuvant therapy. Regarding the last point, Alobid et al., ${ }^{2}$ compared the impact of nasal symptoms and quality of life using the sinonasal symptoms test RSOM-31 and quality of life test SF-36. They found that patients undergoing extended endoscopic skull base surgery showed higher sinonasal symptoms that patients undergoing pituitary surgery and both had mild impairment in quality of life assessed by the SF-36 questionnaire.

\section{Radiological findings}

Postoperative imaging evaluation is one of the cornerstones of monitoring patients undergoing skull base pathology. In order to detect residual lesions, recurrence and/or complications (e.g., mucoceles), postoperative MRI based assessment is one of the fundamental pillars for following patients undergoing skull base pathology. In order to perform a proper assessment of the radiological findings is essential to know the radiological characteristics of the healing process that occurs in the sinonasal cavity; especially it is necessary to take into account the radiological variations of the nasoseptal flap during the healing process, and the different features between inflamed mucosa and tumour infiltrated mucosa. In general, MRI better distinguishes normal and inflamed soft tissues and differentiates between these tissues and tumour. The latter is primarily based on the fact that inflamed mucosa is associated with increased submucosal oedema and increased mucus secretions, both of which are initially $95 \%$ water. Consequently, on T1-weighted MRI sequences, as water has a long relaxation time the mucosa is seen as low signal intensity ("dark"). And on T2-weighted images, water also has a long relaxation time and is seen as high signal intensity ("bright"). ${ }^{46}$ Kang et al., ${ }^{47}$ studied ten patients who underwent endoscopic surgery of the skull base and required reconstruction of the skull base defect by a nasoseptal flap, all patients were evaluated with MRI, and it was concluded that a vital flap is hypo intense on both $\mathrm{T} 1$ and $\mathrm{T} 2$ and in both phases of the MRI (immediate and delayed). Regarding inflammatory tissue differentiation, it is important to distinguish between the presence of the inflammatory process due to the surgery, the presence of granulations, and the presence of tumour recurrence. Som et al. ${ }^{48}$ observed that the inflamed sinus mucosa is characterized by hypo intensity on $\mathrm{T} 1$ and hyper intensity on T2. In contrast, the tumour tissue is usually characterized by hypo intensity on both $\mathrm{T} 1$ and $\mathrm{T} 2$. Therefore to assess tumour tissue/recurrence is better to assess images on $\mathrm{T} 2$ sequence. ${ }^{49}$ In our study we have not observed any tumour recurrence or persistence but we showed that the sinonasal mucosa remains with inflammatory signs up to 12 months after surgery especially on T2weighted images. One has to keep in mind all the exposed evidence when deciding to use other imaging tests such as PET-CT because the inflamed cells also show increased glycolytic activity, consequently inflamed areas cannot be distinguish with tumour tissue..$^{50-53}$

\section{Conclusion}

The endoscopic endonasal skull base surgery is a technique that in recent years has evolved dramatically, emerging as one of the treatments of choice in addressing skull base pathology. While the main objective is tumour resection, there is a growing interest on studying the functional outcome in relation to the quality of life and nasal symptoms. Unfortunately, there are still few studies to perform a standardization of methods that measure functional outcomes after endoscopic skull base surgery. In a future, longitudinal studies are needed to standardize the measurement instruments of quality of life, nasal symptoms and general symptoms suffered by these patients after surgery. 


\section{Acknowledgments}

None.

\section{Conflicts of interest}

Author declares there are no conflicts of interest.

\section{Funding}

None.

\section{References}

1. Kassam A, Mintz A, Gardner P, et al. The expanded endonasal approach for an endoscopic transnasal clipping and aneurysmorrhaphy of a large vertebral artery aneurysm: technical case report. Neurosurgery. 2006;59(Suppl 1):162-165.

2. Alobid I, Ensenat J, Marino Sanchez F, et al. Impairment of olfaction and mucociliary clearance after expanded endonasal approach using vascularized septal flap reconstruction for skull base tumors. Neurosurgery. 2013;72(4):540-546.

3. De Almeida JR, Snyderman CH, Gardner PA, et al. Nasal morbidity following endoscopic skull base surgery: a prospective cohort study. Head Neck. 2011;33(4):547-551.

4. Beule AG. Physiology and pathophysiology of respiratory mucosa of the nose and the paranasal sinuses. GMS Curr Top Otorhinolaryngol Head Neck Surg. 2010;89(Suppl 1):S15-S34.

5. Ginzel A, Illum P. Nasal mucoliliary clearance in patients with septal deviation. Rhinology. 1980;18(4):177-181

6. Georgalas C, Badloe R, Van Furth W, et al. Quality of life in extendedendonasal approaches for skull base tumours. Rhinology. 2012;50(3):255-261.

7. McKenna SP, Doward LC, Alonso J, et al. The QoL-AGHDA: an instrument for the assessment of quality of life in adults with growth hormone deficiency. Qual Life Res. 1999;8(4):373-383.

8. Herschbach P, Henrich G, Strasburger CJ, et al. Development and psychometric properties of a disease-specific quality of life questionnaire for adult patients with growth hormone deficiency. Eur J Endocrinol. 2001;145(3):255-265.

9. Gil Z, Abergel A, Spektor S, et al. Development of a cancer-specific anterior skull base quality of life questionnaire. $J$ Neurosurg. 2004;100(5):813-819.

10. McMillan CV, Bradley C, Gibney J, et al. Preliminary development of the new individualized HDQoL questionnaire measuring quality of life in adulthypopituitarism. $J$ Eval Clin Pract. 2006;12(5):501-514.

11. Webb SM, Badia X, Surinach NL. Validity and clinical applicability of the acromegaly quality of life questionnaire, AcroQoL: a 6-month prospective study. Eur J Endocrinol. 2006;155(2):269-277.

12. Kan P, Cusimano M. Validation of a quality-of-life questionnaire for patients with pituitary adenoma. Can J Neurol Sci. 2006;33(1):80-85.

13. Webb SM, Badia X, Barahona MJ, et al. Evaluation of health-related quality of life in patients with Cushing's syndrome with a new questionnaire. Eur J Endocrinol. 2008; 158(5):623-630.

14. Lovas K, Curran S, Oksnes M, et al. Development of a disease-specific quality of life questionnaire in Addison's disease. J Clin Endocrinol Metab. 2010;95(2):545-551.

15. Little AS, Jahnke $H$, Nakaji $P$, et al. The anterior skull base nasal inventory (ASK nasal inventory): a clinical tool for evaluating rhinological outcomes after endonasal surgery for pituitary and cranial base lesions. Pituitary. 2012;15(4):513-517.
16. Balaker A, Bergsneider M, Martin N, et al. Evolution of sinonasal symptoms following endoscopic anterior skull base surgery. Skull Base. 2010;20(4):254-251.

17. Graham SM, Iseli TA, Karnell LH, et al. Endoscopic approach for pituitary surgery improves rhinologic outcomes. Ann Otol Rhinol Laryngol. 2009;118(9):630-635.

18. Pant H, Bhatki AM, Snyderman $\mathrm{CH}$, et al. Quality of life following endonasal skull base surgery. Skull Base. 2010;20(1):35-40.

19. McCoul ED, Anand VK, Schwartz TH. Improvements in site-specific quality of life 6 months after endoscopic anterior skull base surgery: a prospective study. J Neurosurg. 2012;117(3):498-506.

20. Hart CK, Theodosopoulos PV, Zimmer LA. Olfactory changes after endoscopic pituitary tumour resection. Otolaryngol Head Neck Surg. 2010;142(1):95-97.

21. Rotenberg BW, Saunders S, Duggal N. Olfactory outcomes after endoscopic transsphenoidal pituitary surgery. Laryngoscope. 2011;121(8):1611-1613.

22. Guilemany JM, Mullol J, Picado C. Relation between rhinosinusitis and bronchiectasis. Arch Bronconeumol. 2006;42(3):135-140.

23. Karaman M, Tek A. Deleterious effect of smoking and nasal septal deviation onmucociliary clearance and improvement after septoplasty. Am J Rhinol Allergy. 2009;23(1):2-7.

24. Andersen IB, Camner P, Jensen Pl, et al. A comparison of nasal and tracheobronchial clearance. Arch Environ Health. 1974;29(5):290-293.

25. Armengot Carceller M, Carda Batalla C, Escribano A, et al. Estudio del transporte mucociliar y de la ultraestructura ci-liar nasales en pacientes con sindrome de Kartagener. Arch de Bronconeumologia. 2005;41(1):11-15

26. Passali D, Bellusi L, Blanchini M, et al. Experiences in the determination of nasal mucociliary transport time. Acta Otolaryngol. 1984;97(34):319-323

27. Ducheteau GS, Gramans K, Ludera J, et al. Correlations between nasal ciliary beat frequency and mucous transport rate in volunteers. Laryngoscope. 1985;95(7-1):854-859.

28. Stanley P, Mac Williams L, Greenstone M, et al. Efficacy of saccharin test for screening to detect abnormal mucociliary clearance. $\mathrm{Br} J \mathrm{Dis}$ Chest. 1984;78 (1):62-65.

29. Puchelle E, Aug F, Pham QT, et al. Comparison of three methods for measuring nasal mucociliary clearance in man. Acta Otolaryngol. 1981;91(3-4):297-303.

30. David B. The nasal septum. In: Alan GK, ed. Scott-Brown's Otolaryngology'de. Oxford: Butterworth-Heinemann. 1987;157-158.

31. Shone GR, Yardley MP, Knight LC. Mucociliary function in the early weeks after nasal surgery. Rhinology. 1990;28(4):265-268.

32. Singh M, Chandra M, Gupta SC, et al. Role of measurement of nasal mucociliary clearance by saccharine test as a yard stick of success of functional endoscopic sinus surgery. Indian J Otolaryngol Head Neck Surg. 2010;62(3):289-295.

33. Morton RP. Life satisfaction in patients with head and neck cancer. Clin Otolaryngol Allied Sci. 1995;20(6):499-503.

34. Ware JE. Conceptualizing disease impact and treatment outcomes. Cancer. 1984;53(10 Suppl):2316-2326.

35. Schipper H. Quality of life: principles of the clinical paradigm. $J$ Psychosoc Oncol. 1990;8(2-3):171-185.

36. Eloy JA, Vivero RJ, Hoang K, et al. Comparison of transnasal endoscopic andopen craniofacialresection for malignant tumors of the anterior skullbase. Laryngoscope. 2009;119(5):834-840. 
37. Hanna E, De Monte F, Ibrahim S, et al. Endoscopic resection of sinonasal cancers with and without craniotomy: oncologic results. Arch Otolaryngol Head Neck Surg. 2009; 135(12):1219-1224.

38. Page RC, Hammersley MS, Burke CW. An account of the quality of life of patients after treatment for non-functioning pituitary tumours. Clin Endocrinology. 1997; 46(4):401-406.

39. Johnson MD, Woodburn CJ, Vance ML. Quality of life in patients with pituitary adenoma. Pituitary. 2003;6(2):81-87.

40. Karabatsou K, Okelly C, Ganna A, et al. Outcomes and quality of life assessment in patients undergoing endoscopic surgery for pituitary adenomas. Br J Neurosurg. 2008; 22(5):630-635.

41. Suberman TA, Zanation AM, Ewend MG, et al. Sinonasal quality-oflife before and after endoscopic, endonasal, minimally invasive pituitary surgery. Int Forum Allergy Rhinol. 2011;1(3):161-166.

42. Hanh CA, Dunn RH, Logue PE, et al. Prospective study of neuropsychologic testing and quality-of-life assessment of adults with primary malignant brain tumors. Int J Radiat Oncol Biol Phys. 2003;55(4):992-999.

43. Martinez Devesa P, Barnes ML, Alcock CJ, et al. Evaluation of quality of life and psychiatric morbidity in patients with malignant tumours of the skull base. J Laryngol Otol. 2006;120(12):1049-1054.

44. Amit M, Abergel A, Fliss DM,et al. The clinical importance of qualityof-life scores in patients with skull basetumors: ameta-analysis and review of the literature. Curr Oncol Rep. 2012;14(2):175-181.
45. Castelnuovo P, Lepera D, Turri Zanoni M, et al. Quality of life following endoscopic endonasal resection of anterior skull base cancers. $J$ Neurosurg. 2013;119(6):1401-1409.

46. Fatterpekar GM, Delman BN, Som PM. Imaging the paranasal sinuses: where we are and where we are going. Anat Rec (Hoboken). 2008;291(11):1564-1572.

47. Kang MD, Escott E, Thomas AJ, et al. The MR imaging appearance of the vascular pedicle nasoseptal flap. AJNR Am J Neuroradiol. 2009;30(4):781-786.

48. Som PM, Dillon WP, Curtin HD, et al. Hypointense paranasal sinus foci. Differential diagnosis with MR imaging and relation to CT findings. Radiology. 1990;176(3):777-781.

49. Loevner LA, Sonners AI. Imaging of neoplasms of the paranasal sinuses. Neuroimaging Clin N Am. 2004;14(4):625-646.

50. Diaz RJ, Maggacis N, Zhang S, et al. Determinants of quality of life in patients with skull base chordoma. J Neurosurg. 2014;120(2):528-537.

51. Abergel A, Cavel O, Margalit N, et al. Comparison of quality of life after transnasal endoscopic vs open skull base tumour resection. Arch Otolaryngol Head Neck Surg. 2012;138(2):142-147.

52. Palme CE, Irish JC, Gullane PJ, et al. Quality of life analysis in patients with anterior skull base neoplasms. Head Neck. 2009;31(10):1326-1334.

53. Badia X, Webb SM, Prieto L, et al. Acromegaly quality of life questionnaire (Acro-QOL). Health Qual Life Outcomes. 2004;2:13. 